\title{
Primary or Secondary Anterior Chamber Lens Implantation After Extracapsular Cataract Surgery and Vitreous Loss
}

\author{
P. G. HYKIN, I. D. GARDNER, M. C. CORBETT, H. CHENG \\ Oxford
}

\begin{abstract}
Summary
Whilst an anterior chamber lens implant (AC IOL) can be implanted during extracapsular cataract extraction with vitreous loss managed by anterior vitrectomy, lens implantation as a secondary procedure may avoid complications. We reviewed 47 consecutive cases of vitreous loss, 37 managed with primary and 10 with secondary AC IOLs. There was no significant difference in the level of final visual acuity but, as expected, it was reached earlier in the primary group $(\mathbf{p}<0.001)$. In the secondary group post-operative astigmatism was less marked $(p<0.05)$ and the AC IOL haptic feet were correctly sited in the angle more frequently $(p<0.05)$. Primary implant patients experienced more recurrent attacks of anterior uveitis $(p<0.01)$ although the incidence of cystoid macular oedema and retinal detachment did not differ significantly. The results suggest that correct AC IOL positioning is more likely with a secondary procedure and that post-operative complications are fewer.
\end{abstract}

Vitreous loss is a serious complication of cataract surgery. Its incidence has been reported to be between $0.9 \%$ and $4.2 \% .^{1,2}$ Final visual acuity (VA) is less good than in uncomplicated cases ${ }^{1,3}$ and the incidence of longterm complications is higher. ${ }^{3}$ If the capsule is torn and the tear is small a posterior chamber lens (PC IOL) may be implanted, ${ }^{4}$ but if the tear is large or if there is a zonular tear, an AC IOL may have to be used if implantation is to proceed. ${ }^{5}$ An AC IOL is associated with more complications than a PC IOL,${ }^{3}$ although it is probable that some of these complications, e.g. retinal detachment and cystoid macular oedema are related more to vitreous loss, than the position of the implant. However, other complications such as chronic angle closure, bullous keratopathy, hyphaema and correctopia may be directly related to imperfect positioning of the AC IOL. Correct positioning is therefore critical, but this is difficult to ascertain with precision at the time of surgery. Whether correct positioning is more often achieved with primary or secondary implantation is not clear. Some authors maintain that primary implantation is no more difficult. ${ }^{6,7}$ Others suggest that secondary implantation is preferable because the section required is small and optimal conditions are more likely to be achieved. ${ }^{8}$ To address this question, we reviewed all the patients whose extracapsular cataract extraction was complicated by vitreous loss and who received a primary or secondary lens implant at the Oxford Eye Hospital between January 1986 and June 1989.

From: The Oxford Eye Hospital, Walton Street, Oxford OX2 6AN.

Correspondence to: P G Hykin BSc, FRCS, FCOphth, The Oxford Eye Hospital, Walton Street, Oxford OX2 6AN. 


\section{Methods}

Fifty-four patients were identified as having vitreous loss after cataract extraction. Of these 47 underwent retrospective case note review and follow-up clinical examination (five had died and two refused). There were 37 cases of primary and ten cases of secondary AC IOL implantation. Follow-up time ranged from two to three and a half years. Preoperative VA, intraocular pressure, type of section, additional intraoperative complications, method of vitrectomy, AC IOL make, size, and power, as well as early post-operative complications (either for the initial or the secondary procedure), were obtained from the case notes. At follow-up, VA and refraction were estimated. Parameters from the cornea, anterior chamber, pupil, iris and lens were recorded, introcular pressure measured and gonioscopy performed. The anterior chamber angle appearance was recorded and special attention paid to the position of the implant haptics within the angle (Figs.1, 2, 3). Pupil shape, axis and degree of decentration were recorded, as were AC IOL direction and degree of decentration. Results were analysed for the two groups using Student's t-test and the $\chi^{2}$ test.

\section{Results}

There was no significant difference in the final
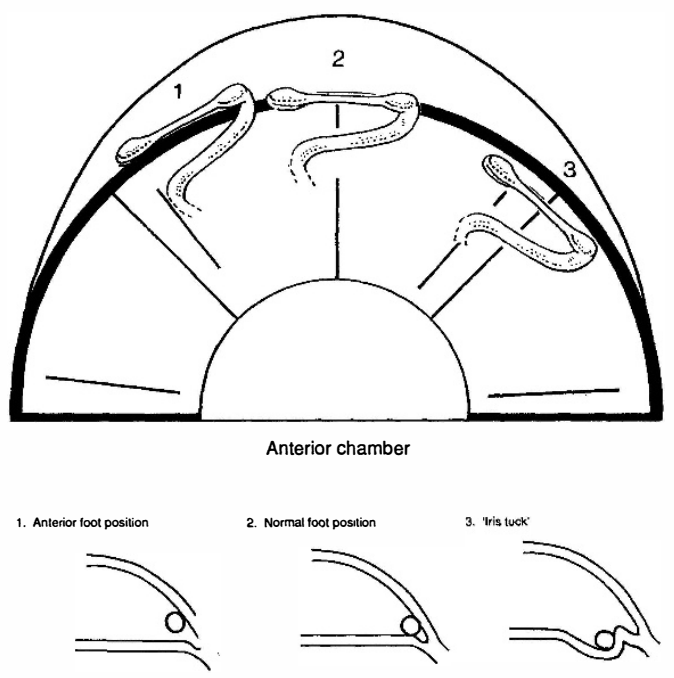

Fig. 1. Anterior chamber intraocular lens haptic foot positions: 1. Anteriorly placed haptic foot. 2. Haptic foot correctly sited in the anterior chamber angle. 3. Iris tuck. post-operative VA between the two groups (Fig. 4). Sixty per cent of all patients achieved a final VA of $6 / 12$ or better, although secondary AC IOL patients took longer to achieve it (mean 9.1 months), than those with primary implants (mean 4.4 months), $(\mathrm{p}<0.001)$. Causes of having a final VA of less than $6 / 12$ are given in Table I. Post-operative astigmatism was greater in the primary implant group (primary AC IOL mean cyl value $=1.92$, secondary $=1.02, \mathrm{p}<0.05)($ Fig. 5), although the cylindrical axis did not differ significantly between the two groups (primary AC IOL mean cyl axis $=89.7$ degrees, secondary $=110.6, p<0.5)$, nor did the final postoperative spherical equivalents. The type of section and whether vitreous was adherent to the section (six cases in the primary group) did not correlate with post-operative complications (Table II). Immediate post-operative uveitis was more common in the primary implant group (seven patients) $(\mathrm{p}<0.01)$, recurrent attacks of anterior uveitis occurring in four of these patients. Neither occurred in patients receiving a secondary AC IOL.

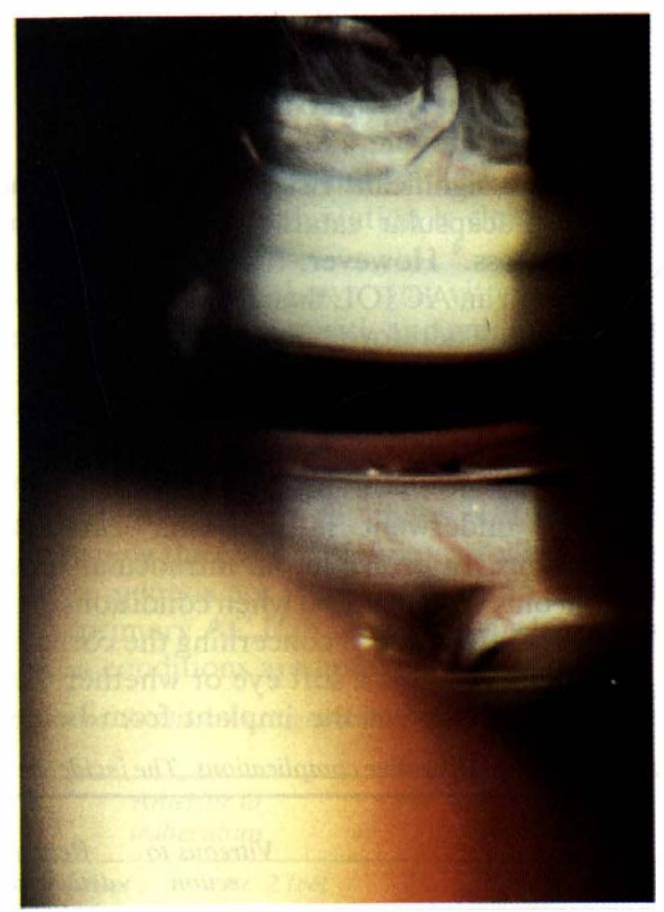

Fig. 2. Anterior chamber intraocular lens haptic foot within the anterior chamber angle. 


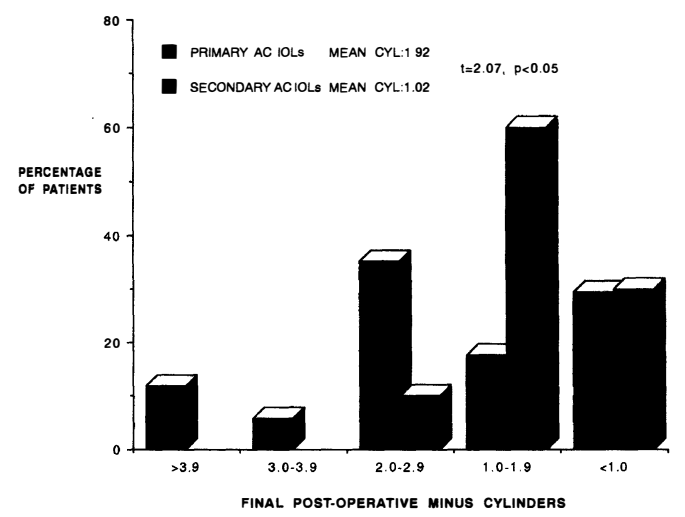

Fig. 3. Final post-operative degree of astigmatism in the primary and secondary implant groups. There was greater astigmatism in the primary group.

There was no significant difference in the incidence of cystoid macular oedema and retinal detachment between the two groups. Correct positioning of the AC IOL haptic feet was achieved significantly more often in the secondary group (Table III). Despite this, the appearance of the anterior chamber angle was similar in the two groups and pupillary area, correctopia and amount and direction of IOL decentration did not differ between them.

\section{Discussion}

There is a significant risk of reduced vision after extracapsular cataract extraction with vitreous loss. ${ }^{9}$ However, functional vision is better with an AC IOL than if the eye remains aphakic. ${ }^{10}$ Therefore, the surgeon has a choice of primary or secondary AC IOL implantation. The only study to compare these alternatives suggested that primary AC IOL implantation was preferable although all patients underwent intracapsular cataract extractions. In principle, an intraocular lens should only be implanted when conditions are ideal. If there is doubt concerning the corneal diameter in what is a soft eye or whether the section will prevent the implant from being held securely, there is no harm in performing a simple anterior vitrectomy and leaving implantation to a later date.

Final visual acuity in this study for both groups of patients (primary group 62\% 6/12 or better and secondary group $60 \% 6 / 12$ or better) were compatible with previously published figures. ${ }^{1-3}$ As expected, patients receiving a secondary AC IOL took longer to reach their final corrected visual acuity $(\mathrm{p}<0.001)$. The period of aphakia before secondary implantation can be managed with an extended wear contact lens until the eye settles down sufficiently, though most patients whose vision is not too poor in the other eye may not require such a measure if the delay before a secondary AC IOL can be implanted is short.

The significant difference in post-operative cyl values $(p<0.05)$ is probably due to corneal astigmatism. ${ }^{11}$ This may be due to incorrect sizing of the implant resulting in anterior segment distortion. It has been suggested that AC IOL tilt can cause significant astigmatism but this is only the case if the tilt is greater than $25^{\circ}$. We did not find a significant difference in the final spherical equivalents implying the accuracy of AC IOL power calculation was not affected by the timing of implantation.

Immediate post-operative uveitis was more common in the primary AC IOL group. This may reflect a longer operation and additional anterior chamber manipulation. Whether it has longterm significance and increases the incidence of cystoid macular oedema and chronic angle closure glaucoma is uncertain. However, in eyes with a previous history of uveitis, it may be advisable to avoid primary IOL implantation for this reason. In addition, over half the patients in the primary group with immediate post-operative uveitis experenced recurrent episodes of anterior uveitis. This did not occur in the secondary AC IOL group.

The incidence of retinal detachment after

Table I. Post-operative complications. The incidence of recurrent uveitis was more frequent in the primary group

\begin{tabular}{lcccccc}
\hline & $\begin{array}{c}\text { Vitreous to } \\
\text { section }\end{array}$ & $\begin{array}{c}\text { Retinal } \\
\text { detachment }\end{array}$ & $\begin{array}{c}\text { Cystoid } \\
\text { macular } \\
\text { oedema }\end{array}$ & $\begin{array}{c}\text { Post-op } \\
\text { uveitis }\end{array}$ & $\begin{array}{c}\text { Recurring ant. } \\
\text { uveitis }\end{array}$ & $\begin{array}{c}\text { Final VA } \\
<6 / 12\end{array}$ \\
\hline Primary AC IOL implants & 6 & 1 & 5 & 7 & 4 & 13 \\
Secondary AC implants & 0 & 1 & 1 & 0 & 0 & 6 \\
\hline
\end{tabular}


Table II. The reasons for patients achieving a final visual acuity of less than 6/12

\begin{tabular}{lccccccc}
\hline & \multicolumn{1}{c}{$\begin{array}{c}\text { Angle } \\
\text { Cetinal } \\
\text { Detach }\end{array}$} & $\begin{array}{c}\text { Closure } \\
\text { glaucoma }\end{array}$ & Iritis & ARMD & $\begin{array}{c}\text { Bullous } \\
\text { keratop }\end{array}$ & $\begin{array}{c}\text { No } \\
\text { cause }\end{array}$ \\
\hline Primary AC IOL & 3 & 1 & 1 & 1 & 3 & 1 & 3 \\
Secondary AC implant & 3 & 1 & 0 & 0 & 0 & 0 & 0 \\
\hline
\end{tabular}

extra-capsular cataract surgery is $0.4 \%-1 \%,^{3}$ compared to $1-3 \%{ }^{6,12}$ if vitreous is lost. The figure for this study (both groups combined) was $2.13 \%$. The numbers are too small for meaningful comparisons between the two groups. The occurrence of clinically evident cystoid macular oedema (defined as a reduction in visual acuity of two or more lines on a Snellen chart in association with clinically evident cystoid changes at the macula) did not differ significantly between the two groups (total incidence $=12.76 \%$ ). After uncomplicated extracapsular cataract extraction the incidence is between $0.9-9 \%{ }^{13,14}$, increasing to $12-18 \%$, after vitreous loss. ${ }^{15,16}$ There are no studies which directly compare the incidence in patients rendered aphakic and those with primary or secondary AC IOLs. The contribution of the IOL is therefore unknown, although it is predicted that implantation further disturbs the vitreous, as may subsequent tilt and decentration of the IOL, iris tuck or haptic foot dislocation through a peripheral iridectomy. If the AC IOL increases the incidence of post-operative uveitis then this may indirectly increase the incidence of cystoid macular oedema. It has been suggested that the incidence of chronic angle closure glaucoma may be increased in patients with AC IOLs ${ }^{17}$ and that the proximity of the haptic feet to the trabecular meshwork is directly responsible for this. ${ }^{18}$

Follow-up gonioscopy of all cases showed that iris tuck was likely to occur in the primary rather than secondary implant group (Table III). However, iris tuck itself did not correlate with the incidence of subsequent uveitis or angle closure glaucoma. Longer follow-up of a larger group may identify significant correlations with these features. The choice between primary or secondary AC IOL implantation is a difficult one to make especially when a serious complication has just been dealt with. Bearing in mind that adverse factors may have led to vitreous loss in a proportion of cases, such unfavourable circumstances may still be prevailing to prejudice successful primary implantation. For example, inadequate anaesthesia in the case of a young myope, through positive orbital pressure and a soft sclera may have contributed to the difficulties of surgery. Such adverse factors will have led to a soft or 'collapsed' globe, making accurate measurement of corneal diameter difficult and the assessment of the iris plane inaccurate; hence, correct positioning of the $\mathrm{AC}$ IOL is less likely. To this must be added the fact that some sections may be ill-suited to support an AC IOL and in these situations, secondary lens implantation is clearly a preferred option.

Our study has shown that vitreous incarceration, recurrent uveitis and greater corneal astigmatism occur significantly more often after primary lens implantation. Our results would suggest that unless conditions are suitable secondary lens implantation should be considered. Therefore, there is a case for informing the patient of this possibility so that the surgeon is not under pressure to proceed to a primary AC IOL after vitreous loss even when conditions are unfavourable.

Table III. Summary of lens haptic foot positions in the two groups. Iris tuck was significantly more common in the primary group

\begin{tabular}{lccccc}
\hline & \multicolumn{2}{c}{ Iris tuck } & \multicolumn{2}{c}{$\begin{array}{c}\text { Anterior to } \\
\text { trabeculum }\end{array}$} & $\begin{array}{c}\text { Normal } \\
\text { position }\end{array}$ \\
\cline { 2 - 6 } & 1 foot & 2 feet & 1 foot & 2 feet & Both Feet \\
\hline Primary AC IOLs & 9 & 3 & 0 & 0 & 25 \\
Secondary IOLs & 1 & 0 & 0 & 0 & 9 \\
\hline
\end{tabular}




\section{References}

${ }^{1}$ Pearson PA, Owen DG, Maliszewski M, Smith JJ: Anterior chamber lens implantation after vitreous loss. Br J Ophthalmol 1989, 73: 596-9.

${ }^{2}$ Mills PV and Robinson GA: Use of the anterior chamber lens in the management of capsule rupture. Eur J I I 1988, 9; 135-42.

${ }^{3}$ Siepser SB and Kline VR: Aborted posterior chamber intraocular lens insertions: A 'second Choyce'. Am Intraocular Implant Soc J 1984, 10: 51-2.

${ }^{4}$ Wang HS: Management of a posterior capsule rupture in planned extracapsular cataract extraction and posterior chamber lens implantation. J Cataract Refract Surg 1986, 12: 73-6.

${ }^{5}$ Jaffe NS: Cataract surgery and its complications. St Louis, Mosby, 1984.

${ }^{6}$ Shammas HJF, Milkie CF: Primary vs. secondary insertion of anterior chamber lenses. Am Intraocular Implant Soc J 1979, 5: 141-2.

${ }^{7}$ Spigelman AV, Lindstrom RL, Nichols BD, Lindquist TD: Visual results following vitreous loss and primary lens implantation. J Cataract Refract Surg 1989, 15: 201-4.

${ }^{8}$ Jaffe NS: Surgical results of cataract and lens implant surgery, In: Klein EA, ed. Symposium on cataract surgery. Trans New Orleans Acad Ophthalmol St Louis: Mosby, 1983, 226-35.

${ }^{9}$ Kennedy JE, Flaherty MP, Hunyor AB, Robinson LP: Evaluation of 967 consecutive intraocular implants. Aust NZ J Ophthalmol 1985, 13: 349-52.
${ }^{10}$ Shammas HJF and Milkie CF: Secondary implantation of anterior chamber lenses. Am Intraocular Implant Soc J 1983, (9): 313-16.

${ }^{11}$ Maltzman BA, Haupt EJ, Capiello L, Cinotti DJ: Anterior chamber implants and post-operative astigmatism. CLAO 1986, 12: 32-5.

${ }^{12}$ Hurite FG, Sorr EM, Everett WG: The incidence of retinal detachment following extracapsular cataract extraction: A ten year study. Ophthalmology 1985, 92: 1096-1101.

${ }^{13}$ Harris WS , Taylor BC, Winslow RL: Cystoid macular oedema following intraocular lens implantation. Ophthalmic Surg 1977, 8: 134-7.

${ }^{14}$ Chambers WS: Phacoemulsification and the retina. Cystoid macular odema. Ophthalmology 1979, 86: 2019-22.

${ }^{15}$ Berger BB, Zweig KO, Peyman GA: Vitreous loss managed by anterior vitrectomy: long-term follow-up of 59 cases. Arch Ophthalmol 1980, 98: 1245-7.

${ }^{16}$ Jaffe NS, Clayman HM, Jaffe MS: Cystoid macular oedema after intracapsular and extracapsular cataract extraction with and without an intraocular lens. Ophthalmology 1982, 89: 25-9.

${ }^{17}$ Apple DJ, Brems RN, Park RB, Kawka-Van Norman D: Anterior chamber lenses. Part 1: Complications and pathology and a review of design. $J$ cataract Refract Surg 1987, 13: 158-73.

${ }^{18}$ Boerner CF and Thrasher BH: Complications from anterior chamber lenses: Report of cases. Ann Ophthalmol 1984, 16: 742-9. 